\title{
Retrieval of Vegetation Indices Related to Leaf Water Content from a Single Index: A Case Study of Eucalyptus globulus (Labill.) and Pinus radiata (D. Don.)
}

\author{
Juan Villacrés ${ }^{1,+}+\mathbb{D}$, Andrés Fuentes ${ }^{2,+}$, Pedro Reszka ${ }^{3,+}\left(\mathbb{D}\right.$ and Fernando Auat Cheein ${ }^{1, *,+(\mathbb{D})}$ \\ 1 Department of Electronic Engineering, Universidad Técnica Federico Santa María, Av. España 1680, \\ Valparaiso 2390123, Chile; juan.villacres@sansano.usm.cl \\ 2 Department of Industrial Engineering, Universidad Técnica Federico Santa María, Av. España 1680, \\ Valparaiso 2390123, Chile; andres.fuentes@usm.cl \\ 3 Faculty of Engineering and Sciences, Universidad Adolfo Ibáñez, Santiago 7941169, Chile; \\ pedro.reszka@uai.cl \\ * Correspondence: fernando.auat@usm.cl \\ + These authors contributed equally to this work.
}

check for updates

Citation: Villacrés, J.; Fuentes, A.; Reszka, P.; Cheein, F.A. Retrieval of Vegetation Indices Related to Leaf Water Content from a Single Index: A Case Study of Eucalyptus globulus (Labill.) and Pinus radiata (D. Don.). Plants 2021, 10, 697. https://doi.org/ $10.3390 /$ plants10040697

Academic Editor: Daniel Sánchez-Mata

Received: 21 March 2021

Accepted: 28 March 2021

Published: 5 April 2021

Publisher's Note: MDPI stays neutral with regard to jurisdictional claims in published maps and institutional affiliations.

Copyright: (C) 2021 by the authors. Licensee MDPI, Basel, Switzerland. This article is an open access article distributed under the terms and conditions of the Creative Commons Attribution (CC BY) license (https:// creativecommons.org/licenses/by/ $4.0 /)$.

\begin{abstract}
The vegetation indices derived from spectral reflectance have served as an indicator of vegetation's biophysical and biochemical parameters. Some of these indices are capable of characterizing more than one parameter at a time. This study examines the feasibility of retrieving several spectral vegetation indices from a single index under the assumption that all these indices are correlated with water content. The models used are based on a linear regression adjusted with least squares. The spectral signatures of Eucalyptus globulus and Pinus radiata, which constitute $97.5 \%$ of the forest plantation in Valparaiso region in Chile, have been used to test and validate the proposed approach. The linear models were fitted with an independent data set from which their performance was assessed. The results suggest that from the Leaf Water Index, other spectral indices can be recovered with a root mean square error up to 0.02 , a bias of $1.12 \%$, and a coefficient of determination of 0.77 . The latter encourages using a sensor with discrete wavelengths instead of a continuum spectrum to estimate the forestry's essential parameters.
\end{abstract}

Keywords: fuel moisture content; vegetation indices; spectral reflectance; Eucalyptus globulus; Pinus radiata

\section{Introduction}

The use of sensors operating in the electromagnetic (EM) spectrum has allowed the estimation of several biophysical parameters in forest and urban environments $[1,2]$. Such estimates employ narrow bands of the EM spectrum, spectral transformations (e.g., derivatives, continuum removal, wavelets), or vegetation indices (VIs). The latter has been used in qualitative and quantitative studies of vegetation on a temporal and spatial scale [3,4]. Vegetation indices are structured from a limited set of wavelengths; VIs attempt to maximize sensitivity to a biophysical parameter while minimizing adverse effects (e.g., atmospheric composition and variations in canopy background) [5].

Some of the spectral indices are used to predict more than one parameter at a time, on scales ranging from leaf level to canopy level, and even on global scales. For example, one of the most common VI, the Normalized Difference Vegetation Index (NDVI), is used in applications to assess biomass, phenology, Leaf Area Index, plant growth, among others [2,5]. Another spectral index is the Double Difference Index (DDI), developed to evaluate chlorophyll levels, but it has also presented a high correlation with the equivalent water thickness [6,7]. Li and coworkers evaluated several chlorophyll-sensitive spectral indices to recover the nitrogen content in the vegetation [8]. Since each individual of a given plant species will have a specific spectral signature which depends on its biophysical 
and biochemical state and, therefore, on environmental conditions, it can be argued that, through the use of spectral reconstruction techniques based on data analysis, the characterization of several vegetation parameters can be performed from a single vegetation index.

In our previous work [9], we studied the correlation of several vegetation indices with the water content in the leaves of Eucalyptus globulus and Pinus radiata. Given the coefficient of determination values, we hypothesized that it is possible to estimate some spectral indices using only the most suitable one used to recover the moisture content. In this brief, 18 spectral indices related to water content are studied, and the most suitable one-from a water content perspective-is selected to recover the remaining ones. To validate this hypothesis, we carried out a dehydration process and worked with two data sets, one for fitting and the other for validating the model. The specific objectives of this study are (1) to develop a model to select the most appropriate index to recover moisture content; (2) to estimate the remaining seventeen water-related spectral indices from the index chosen in (1); and (3) to evaluate the performance of the model in terms of mean square error, coefficient of determination, and percent bias.

\section{Materials and Methods}

Figure 1 represents the work-flow followed in this study. It began with the acquisition stage, where leaves were collected and their reflectance spectrum measured. With this information, the fuel moisture content (FMC) and the eighteen vegetation indices were obtained. Then, the relationship of the fuel moisture content and the vegetation indices was expressed in terms of the coefficient of determination $\left(R^{2}\right)$. The index with the highest $R^{2}$ was selected as suitable, and then the models were obtained to recover the rest of the indices from the selected one. Finally, a validation stage was carried out with an independent dataset. Each of these stages is detailed below.

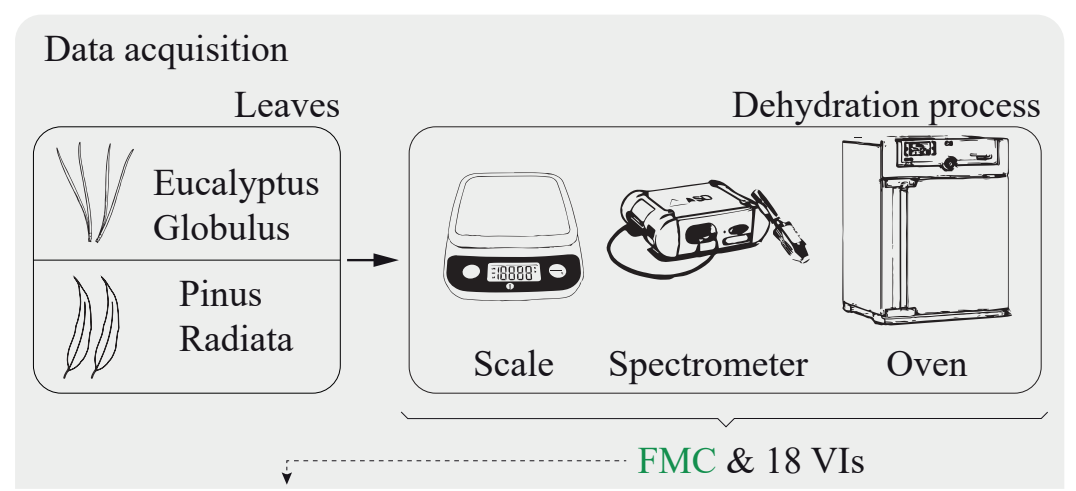

Modeling fuel moisture content
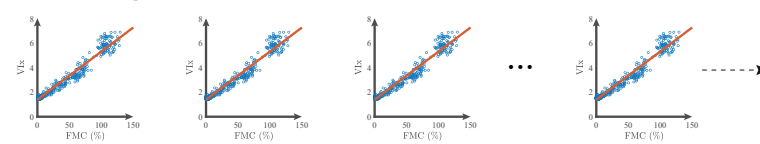

Select the VI with the FMC vs $\mathrm{VI}_{1}$ $\mathrm{FMC}$ vs $\mathrm{VI}_{2}$ FMC vs $\mathrm{VI}_{3}$ FMC vs $\mathrm{VI}_{18}$ ì

Modeling vegetation indices
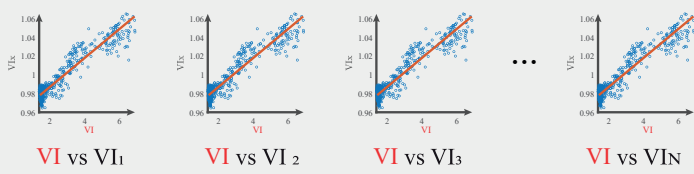

Test in an highest $\mathrm{R}^{2}$

VI vs VI 2

$\mathrm{VI}$ vs $\mathrm{VI}_{3}$

VI vs VIN

$\rightarrow$ independent

dataset

RMSE, $\mathrm{R}^{2}$, and bias (\%)

Figure 1. General scheme of the measurement and modeling process of the vegetation indices. 


\subsection{Leaf Sampling}

In the region of Valparaiso, located in central Chile, a field sampling of Pinus radiata and Eucalyptus globulus leaves was carried out. These leaves were collected from the lower part of the canopy during four measurement campaigns. The months in which these samples were obtained were July, August and September 2018, and the last one in January 2020. In the first three campaigns, a total of 90 samples were obtained, while in the last one, 27 samples were collected (per each species). This separation is due to the fact that this last data set will be used to evaluate the performance of the models.

Once the branches were cut from the trees, they were stored in plastic bags to minimize aging effects. The samples were taken to the laboratory in less than one hour to start the measuring process.

\subsection{Reflectance Measurement and Dehydration Process}

The Eucalyptus leaves were detached individually from the branches; on the contrary, as Pinus needles have an acicular shape, they were arranged in batches of approximately $5 \mathrm{~g}$. At this point, the leaves were considered alive, their masses were registered with a balance and their reflectance was recorded with the ASD spectrometer. To perform the spectral measurement, each leaf was placed on a panel with constant reflectance throughout the spectrum. Then the contact probe, illuminated with a tungsten filament, was placed over the samples, and the spectral signature of each sample was recorded three times. The spectrometer was calibrated with a Spectralon before use, and after 30 measurements.

Since the models to be used depended on the variation of water content in the leaves, a dehydration process was carried out to have a wide range of samples with different moisture content levels. This process consisted of placing the leaves in a drying oven at $65{ }^{\circ} \mathrm{C}$ for $15 \mathrm{~min}$ for Eucalyptus leaves and $60 \mathrm{~min}$ for Pinus needles. After the drying process, the spectrum and mass were measured. This dehydration was repeated a total of three times, following the guidelines presented in $[9,10]$. Finally, to obtain the completely dry leaf mass, a 24-h drying process was carried out. In summary, five mass and reflectance values were measured for each vegetation sample. Table 1 lists the technical characteristics of the equipment used in this procedure. A general scheme of the measurement process is given at the top of Figure 1.

Table 1. Technical characteristics of the instruments.

\begin{tabular}{ccc}
\hline Instrument & Specifications & \\
\hline Spectrometer & Model & Terraspec 4 Hi-Res \\
& Manufacturer & ASD \\
& Range & $350-2500 \mathrm{~nm}$ \\
& Spectral resolution & $3 \mathrm{~nm}$ at $700 \mathrm{~nm}, 6 \mathrm{~nm}$ at $1400 \mathrm{~nm}$ \\
\hline Scale & Model & PFB $120-3$ \\
& Manufacturer & $\mathrm{KERN}$ \\
& Max. weighing & $120 \mathrm{~g}$ \\
& Reproducibility & $0.001 \mathrm{~g}$ \\
\hline Oven & Model & $\mathrm{UN} 30$ \\
& Manufacturer & Memmert \\
& Range & $20^{\circ} \mathrm{C}$ to $30{ }^{\circ} \mathrm{C}$ \\
& Temperature accuracy & up to $99.9^{\circ} \mathrm{C}: 0.1$ \\
\hline
\end{tabular}

\subsection{Moisture Content and Vegetation Indices}

Once the measurement process was complete, the FMC was calculated as follows:

$$
F M C=\frac{W_{f, t}-W_{d}}{W_{d}}
$$


where $W_{f, t}$ is the weight of the leaf at the time $t$, and $W_{d}$ is the dried leaf's mass. Several researches have developed spectral indices with a high correlation with the moisture content. In this regard, we selected 18 vegetation indices previously reviewed in [9]. The complete list of indices is shown in Table 2.

Table 2. Vegetation indices used in the estimation of moisture content, including their acronym, name, formulation and source.

\begin{tabular}{cccc}
\hline Acronym & Vegetation Index & Formulation & Source \\
\hline DDI & Double Difference Index & $2 R_{1530}-R_{1005}-R_{2055}$ & {$[6,7]$} \\
EVI & Enhanced Vegetation Index & $2.5\left(R_{\text {nir }}-R_{\text {red }}\right) /\left(R_{\text {nir }}+6 R_{\text {red }}-7.5 R_{\text {blue }}+1\right)$ & {$[11]$} \\
fWBI & Floating-position Water Band Index & $R_{900} / \min \left(R_{930}-R_{980}\right)$ & {$[12]$} \\
LWI & Leaf Water Index & $R_{1300} / R_{1450}$ & {$[13]$} \\
MSI & Moisture Stress Index & $R_{1600} / R_{820}$ & $R_{1650} / R_{1230}$ \\
MSI1 & Moisture Stress Index 1 & $R_{1650} / R_{830}$ & {$[14]$} \\
MSI2 & Moisture Stress Index 2 & $\left(R_{850}-R_{1650}\right) /\left(R_{850}+R_{1650}\right)$ \\
NDII & Normalized Difference Infrared Index & $\left(R_{860}-R_{1240}\right) /\left(R_{860}+R_{1240}\right)$ & {$[15]$} \\
NDWI1 & Normalized Difference Water Index 1 & $\left(R_{870}-R_{1260}\right) /\left(R_{870}+R_{1260}\right)$ & {$[16]$} \\
NDWI2 & Normalized Difference Water Index 2 & $\left(R_{1640}-R_{858}\right) /\left(R_{1640}+R_{858}\right)$ & {$[17]$} \\
SIWSI & Shortwave Infrared Water Stress & $R_{860} / R_{1240}$ & {$[18]$} \\
SRWI & Simple Ratio Water Index & $R_{1350} / R_{870}$ & {$[20]$} \\
SRWI1 & Simple Ratio Water Index 1 & $R_{880} / R_{1265}$ & {$[18]$} \\
SRWI2 & Simple Ratio Water Index 2 & $R_{1650} / R_{2220}$ & {$[18]$} \\
TM57 & Ratio of Thematic Mapper Band 5 to Band 7 & $\left(R_{\text {green }}-R_{\text {red }}\right) /\left(R_{\text {green }}+R_{\text {red }}-R_{\text {blue }}\right)$ & $R_{970} / R_{900}$ \\
VARI & Visible Atmospheric Resistant Index & $R_{900} / R_{970}$ & {$[22]$} \\
WBI & Water Band Index & & {$[23]$} \\
WI & Water Index & & \\
\hline
\end{tabular}

\subsection{Vegetation Index Retrieval}

As stated in Section 1, this study aimed to retrieve water-related vegetation indices from a single index. Therefore, it was crucial to determine which index will be the basis for recovering the remaining 17 . In this regard, the FMC was correlated from each spectral index using a linear model as shown in Equation (2):

$$
F M C=\alpha_{1, x} V I_{x}+\alpha_{2, x}
$$

where $\alpha_{1, x}, \alpha_{2, x}$ are the parameters of the linear model fitted with least squares, the suffix $x \in\{1,2,3, \ldots, 18\}$ represents each one of the indices in Table 2. The model with the highest coefficient of determination is selected and named with suffix $H$. The FMC of the selected index $V I_{H}$ is equalized to each of the remaining spectral index models (indicated as $\left.V I_{N}\right)$ from this model stack. The final linear model with input $V I_{H}$, and the output each of the resting 17 indices is shown in Equation (3):

$$
V I_{N}=\frac{1}{\alpha_{1, N}}\left(\alpha_{1, H} \cdot V I_{H}+\alpha_{2, H}-\alpha_{2, N}\right)
$$

\subsection{Model Evaluation Metrics}

The validation stage was conducted on an independent data set. The performance of the linear models was tested based on three metrics: coefficient of determination $R^{2}$, Root Mean Square Error (RMSE) as shown in Equation (4); and percentage bias (bias), see Equation (5). The first indicated how well the actual and predicted values of the VI fitted together. The second quantified the error made in the prediction; the lower the RMSE value, the better the model. The percentage bias indicated the estimated data's tendency to be 
larger or smaller than their actual values. Positive bias values represented overestimation, and negative bias values represented underestimation [25].

$$
\begin{aligned}
\text { RMSE } & =\sqrt{\frac{1}{n} \sum_{i=1}^{n}\left(\hat{V I} I_{i}-V I_{i}\right)^{2}} \\
\text { bias } & =\frac{V I-\hat{V I}}{V I} \times 100 \%
\end{aligned}
$$

where $\hat{V} I_{i}$ is the prediction of the $i$ th-vegetation index sample, $V I_{i}$ is the actual value of the $i$ th-vegetation index, and $n$ is the number of samples.

\subsection{Non-Water Content Related VIs}

We also estimated five vegetation indices-different from the 18 VIs chosen in Table 2based on the index selected in Section 2.4. These VIs provided information on nitrogen content, anthocyanin, and carotenoid content. Besides, we included the most widespread VI in vegetation assessment, the NDVI [26]. Table 3 shows the acronym, formula, and reference information for each index.

Table 3. Vegetation indices non-related to the estimation of moisture content, including their acronym, name, formulation and source.

\begin{tabular}{cccc}
\hline Acronym & Vegetation Index & Formulation & Source \\
\hline NRI & Nitrogen reflectance index & $\left(R_{570}-R_{670}\right) /\left(R_{570}+R_{670}\right)$ & {$[27]$} \\
ARI & Anthocyanin reflectance index & $\left(1 / R_{550}\right)-\left(1 / R_{700}\right)$ & {$[28]$} \\
CI & Carotenoid Index & $R_{520} / R_{500}$ & {$[29]$} \\
NDVI & Normalized Difference Vegetation Index & $\left(R_{\text {nir }}-R_{\text {red }}\right) /\left(R_{\text {nir }}+R_{\text {red }}\right)$ & {$[30]$} \\
\hline
\end{tabular}

\section{Results}

As reported in Section 2, the data from the first three measurement campaigns were used to fit the models, while the last one was used to validate them. The time between the measurement of these two sets was 15 months and thus they were considered independent sets. The first column of Figure 2 presents the group used in the linear modeling, while the second column represents the validation set. The dehydration process resulted in a variation of the FMC between $0 \%$ when the leaves were dry (after $24 \mathrm{~h}$ in the oven), and a maximum of $157.68 \%$ and $180.04 \%$ for Pinus needles and Eucalyptus leaves, respectively. Nevertheless, we limited our work to water contents higher than $30 \%$ and $50 \%$ for Pinus and Eucalyptus, respectively. Those thresholds were defined according to the results obtained in [31,32], for Pinus and Eucalyptus species. These values were obtained under drought stress conditions; lower values of water content caused the plant to show traits of mortality [31]. 

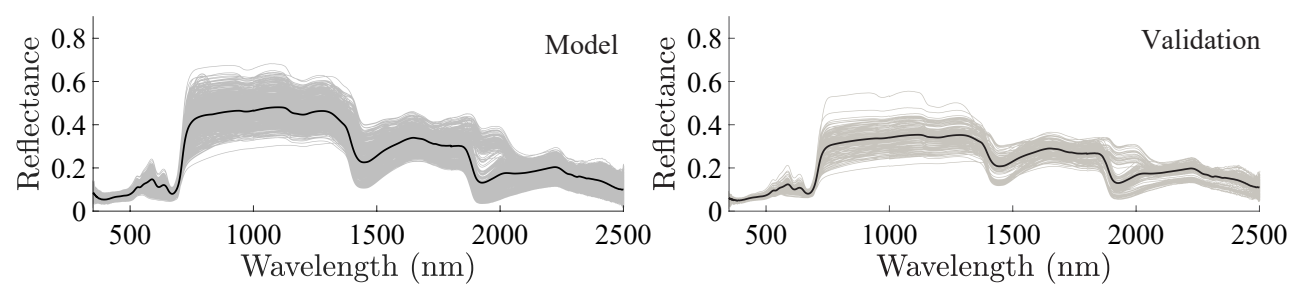

(a)
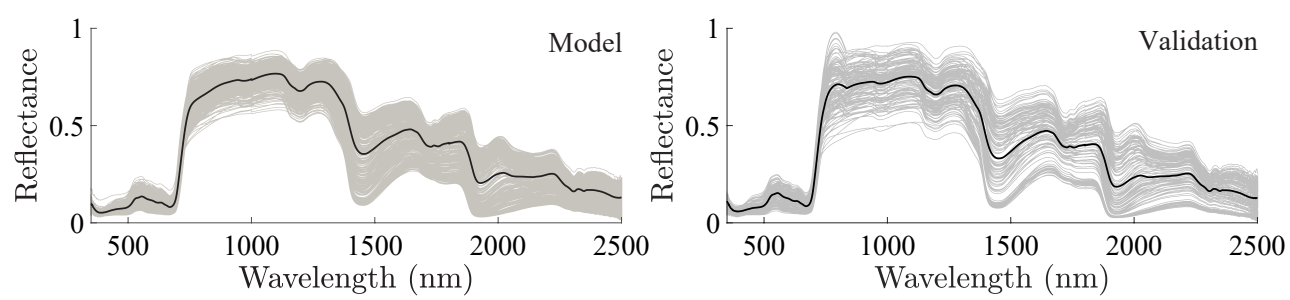

(b)

Figure 2. Set of samples used for fitting and validating the models. In black line the average reflectance spectra and in grey the reflectance of the individual samples. Where: (a) Pinus radiata and (b) Eucalyptus globulus.

\subsection{Model Fitting}

Table 4 shows that the maximum value of $R^{2}$ for both species was 0.8699 , and was obtained with the Leaf Water Index (LWI) for Eucalyptus globulus. Also, this same index for Pinus radiata was the highest with $R^{2}=0.7742$. Thus, the LWI was selected as a suitable index to retrieve the rest of the indices. As supplementary material, the reader can refer to Appendix A for the variation of the 18 vegetation indices as function of FMC for Pinus radiata and Eucalyptus globulus.

Table 4. Coefficient of determination for the FMC vs VI models using the fitting set.

\begin{tabular}{ccc}
\hline Vegetation Index & P. radiata & E. globulus \\
\hline DDI & 0.5263 & 0.7379 \\
EVI & 0.2898 & 0.2061 \\
fWBI & 0.6286 & 0.6567 \\
LWI & 0.7742 & 0.8699 \\
MSI & 0.6668 & 0.7892 \\
MSI & 0.6497 & 0.7637 \\
MSI2 & 0.6566 & 0.7559 \\
NDII & 0.6599 & 0.7600 \\
NDWI1 & 0.5702 & 0.6062 \\
NDWI2 & 0.5643 & 0.6042 \\
SIWSI & 0.6681 & 0.7696 \\
SRWI & 0.5710 & 0.6068 \\
SRWI1 & 0.7321 & 0.7818 \\
SRWI2 & 0.5733 & 0.6146 \\
TM57 & 0.6450 & 0.7497 \\
VARI & 0.5101 & 0.1525 \\
WBI & 0.6359 & 0.6606 \\
WI & 0.6344 & 0.6616 \\
\hline
\end{tabular}

The 17 remaining spectral indices were calculated following Equation (3). For both species, the $R^{2}$, the RMSE, and the percentage bias are depicted in Figure 3 . The percentage bias was expressed with two different colors for positive and negative values-this distinction was made because the axis of the ordinates was logarithmic. 

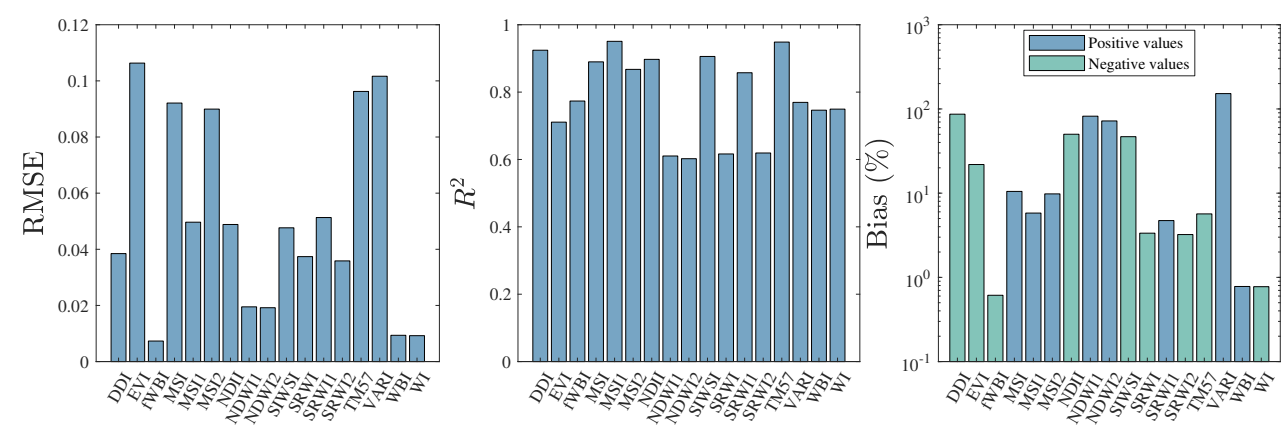

(a)
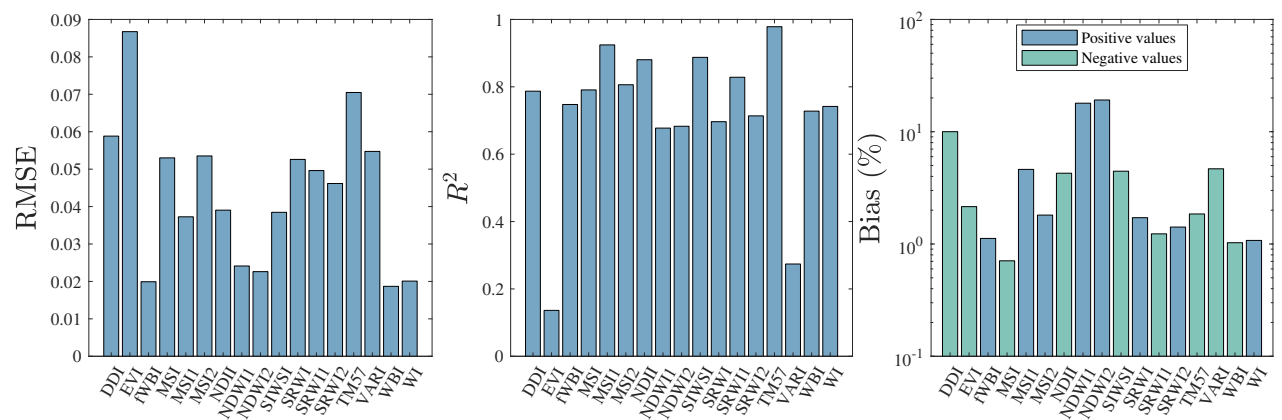

(b)

Figure 3. Evaluation of model performance for retrieval of vegetation indices. Where: (a) Pinus radiata and (b) Eucalyptus globulus.

The spectral indices recovered from the LWI with the lowest RMSE were fWBI, WI, WBI, with values less than 0.0094 and 0.0201 for Pinus and Eucalyptus, respectively. On the other hand, the TM57 and MSI1 indices presented a coefficient of determination higher than 0.9244 in both species. Finally, considering the indices with lower RMSE and $R^{2}$ values; the WBI and WI indices had an absolute percentage bias lower than $1.07 \%$ for both species. It is worth noting that none of the wavelengths of the LWI formulation were contained in the five indices mentioned above.

In addition to these five vegetation indices, other spectral indices with significant evaluation metrics were obtained. In particular, for Pinus radiata, MSI, MSI2, NDII, SIWSI and SRWI1 with an RMSE was lower than 0.092, and the $R^{2}$ was higher than 0.85. On the other hand, for Eucalyptus globulus, the spectral indices MSI, MSI2, NDII, SIWSI and SRWI1 had an RMSE lower than 0.054, and $R^{2}$ higher than 0.791 .

\subsection{Retrieval of Non-Water Content Related VIs}

After observing that the LWI was able to recover several vegetation indices related to water content, we used such an index to estimate other VIs not associated with moisture content (see Table 3). The results indicated that the LWI was suitable to estimate the VIs presented in Table 5 with an $R^{2}$ higher than 0.71, an RMSE lower than 0.0908 for Pinus radiata. For Eucalyptus globulus, the coefficient of determination is more elevated than 0.7475, and an RMSE lower than 0.0588 .

Table 5. Evaluation of Leaf Water Index (LWI) to retrieve non-water content related vegetation indices (VIs).

\begin{tabular}{ccccccc}
\hline & \multicolumn{3}{c}{ Pinus radiata } & \multicolumn{3}{c}{ Eucalyptus globulus } \\
\hline & RMSE & $\boldsymbol{R}^{\mathbf{2}}$ & Bias (\%) & RMSE & $\boldsymbol{R}^{\mathbf{2}}$ & Bias (\%) \\
\hline NRI & 0.0338 & 0.9243 & -75.9749 & 0.0588 & 0.7870 & -9.9942 \\
ARI & 0.0073 & 0.7735 & -0.6143 & 0.0201 & 0.7475 & 1.0940 \\
CI & 0.0898 & 0.8898 & 10.2368 & 0.0530 & 0.7908 & -0.6564 \\
NDVI & 0.0464 & 0.9507 & 5.4369 & 0.0364 & 0.9244 & 4.5324 \\
\hline
\end{tabular}




\title{
4. Discussion
}

The assumption that the adjustment and validation sets are independent can be supported due to the difference in the mean spectrum of the two sets (see black line in Figure 2). Additionally, the spread of the individual reflectance spectra shows noticeable differences between the model and validation sets, as seen in Figure 2.

The relationship between the FMC and the eighteen VIs understudy is expressed as a coefficient of determination in Table 4. In general, the mean value of the $R^{2}$ coefficient, for the ten indices with the highest coefficient of determination, is 0.6723 and 0.7639 for Pinus radiata and Eucalyptus globulus, respectively. Such values suggest that given the correlation of spectral indices and water content, it would be possible to use only one to determine the others. The selection of the most suitable spectral index was made based on the coefficient of determination. The values obtained for RMSE, $R^{2}$, and bias suggest that it is possible to estimate several related spectral indices from a single one, in specific, Leaf Water Index (LWI). On the other hand, the results obtained when retrieving VIs that are not related to water content from the LWI point to the possibility of using such index to estimate a wide range of VIs; however, further work is needed in this area.

\section{Conclusions}

This study presents the findings on the potential of exploiting the relationship between FMC and vegetation indices to estimate the values of several moisture-related spectral indices form the knowledge of a single index. The work has focused on linear models, which are adjusted with data obtained in field sampling. The results suggest that it is possible to retrieve some vegetation indices from a Leaf Water Index (LWI). Specifically, the fWBI, WBI, WI can be recovered from the LWI up to an RMSE $=0.0201 ; R^{2}=0.77$; and bias $=1.12 \%$ for both species. The main use of such a method is for the use of airborne sensors with discrete wavelengths instead of a continuous spectrum one to estimate vegetation indices.

Author Contributions: conceptualization, F.A.C., A.F. and P.R.; methodology, J.V.; software, J.V.; validation, J.V.; formal analysis, F.A.C. and J.V.; investigation, J.V.; resources, F.A.C.; data curation, A.F. and P.R.; writing-original draft preparation, J.V., F.A.C., A.F. and P.R.; writing-review and editing, F.A.C., A.F.; visualization, J.V.; supervision, F.A.C.; project administration, A.F.; funding acquisition, A.F. All authors have read and agreed to the published version of the manuscript.

Funding: This research was funded by ANID PIA/ANILLO ACT172095, ANID FB0008.

Data Availability Statement: The data presented in this report are available on request from the corresponding author.

Acknowledgments: The authors would like to thank to Agencia Nacional de Investigación y Desarrollo (ANID) PFCHA/DoctoradoNacional/2020-2120068, Universidad Técnica Federico Santa María, Dirección General de Investigación, Innovación y Postgrado (DGIIP), Fondecyt 1201319, and PIIC $25 / 2020$.

Conflicts of Interest: The authors declare no conflict of interest.

\author{
Abbreviations \\ EM Electromagnetic \\ FMC Fuel Moisture Content \\ $R^{2} \quad$ Coefficient of determination \\ VI Vegetation index
}

The following abbreviations are used in this manuscript: 


\section{Appendix A. Vegetation Indices Variation versus Fuel Moisture Content}


Figure A1. VIs variation as function of Fuel Moisture Content for Pinus radiata. 

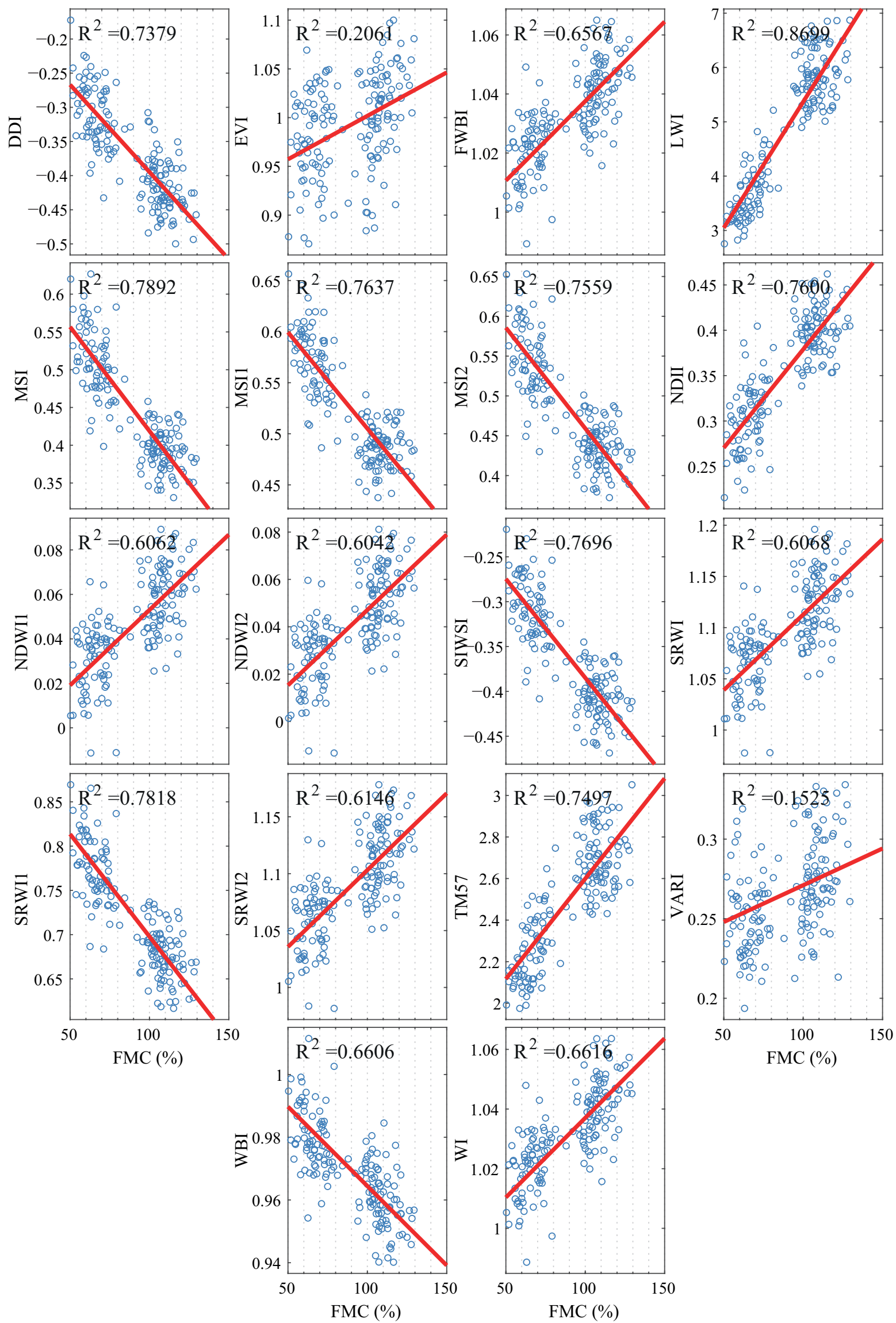

Figure A2. VIs variation as function of Fuel Moisture Content for Eucalyptus globulus. 


\section{References}

1. Lutz, D.A.; Washington-Allen, R.A.; Shugart, H.H. Remote sensing of boreal forest biophysical and inventory parameters: A review. Can. J. Remote Sens. 2008, 34, S286-S313. [CrossRef]

2. Cârlan, I.; Mihai, B.A.; Nistor, C.; Große-Stoltenberg, A. Identifying urban vegetation stress factors based on open access remote sensing imagery and field observations. Ecol. Inform. 2020, 55, 101032. [CrossRef]

3. Xue, J.; Su, B. Significant remote sensing vegetation indices: A review of developments and applications. J. Sens. 2017, 2017. [CrossRef]

4. Freitas, W.; Gois, G.; Pereira, E.; Oliveira Junior, J.; Magalhães, L.; Brasil, F.; Sobral, B. Influence of fire foci on forest cover in the Atlantic Forest in Rio de Janeiro, Brazil. Ecol. Indic. 2020, 115, 106340. [CrossRef]

5. Pôças, I.; Calera, A.; Campos, I.; Cunha, M. Remote sensing for estimating and mapping single and basal crop coefficientes: A review on spectral vegetation indices approaches. Agric. Water Manag. 2020, 106081. [CrossRef]

6. Le Maire, G.; Francois, C.; Dufrene, E. Towards universal broad leaf chlorophyll indices using PROSPECT simulated database and hyperspectral reflectance measurements. Remote Sens. Environ. 2004, 89, 1-28. [CrossRef]

7. Wang, Q.; Li, P. Hyperspectral indices for estimating leaf biochemical properties in temperate deciduous forests: Comparison of simulated and measured reflectance data sets. Ecol. Indic. 2012, 14, 56-65. [CrossRef]

8. Li, F.; Miao, Y.; Feng, G.; Yuan, F.; Yue, S.; Gao, X.; Chen, X. Improving estimation of summer maize nitrogen status with red edge-based spectral vegetation indices. Field Crop. Res. 2014, 111-123. [CrossRef]

9. Villacrés, J.; Arevalo-Ramirez, T.; Fuentes, A.; Reszka, P.; Cheein, F. Foliar moisture content from the spectral signature for wildfire risk assessments in Valparaíso-Chile. Sensors 2019, 19, 5475. [CrossRef]

10. Arevalo-Ramirez, T.; Villacrés, J.; Fuentes, A.; Reszka, P.; Auat Cheein, F. Moisture content estimation of Pinus radiata and Eucalyptus globulus from reconstructed leaf reflectance in the SWIR region. Biosyst. Eng. 2020, 193, 187-205. [CrossRef]

11. Gao, X.; Huete, A.R.; Ni, W.; Miura, T. Optical—Biophysical relationships of vegetation spectra without background contamination. Remote Sens. Environ. 2000, 74, 609-620. [CrossRef]

12. Strachan, I.B.; Pattey, E.; Boisvert, J.B. Impact of nitrogen and environmental conditions on corn as detected by hyperspectral reflectance. Remote Sens. Environ. 2002, 80, 213-224. [CrossRef]

13. Seelig, H.D.; Hoehn, A.; Stodieck, L.; Klaus, D.; Adams Iii, W.; Emery, W. The assessment of leaf water content using leaf reflectance ratios in the visible, near-, and short-wave-infrared. Int. J. Remote Sens. 2008, 29, 3701-3713. [CrossRef]

14. Hunt Jr, E.R.; Rock, B.N. Detection of changes in leaf water content using near-and middle-infrared reflectances. Remote Sens. Environ. 1989, 30, 43-54. [CrossRef]

15. Rock, B.; Vogelmann, J.; Williams, D.; Vogelmann, A.; Hoshizaki, T. Remote Detection of Forest Damage: Plant responses to stress may have spectral "signatures" that could be used to map, monitor, and measure forest damage. Bioscience 1986, 36, 439-445. [CrossRef]

16. Hardisky, M.; Klemas, V.; Smart, M. The influence of soil salinity, growth form, and leaf moisture on the spectral radiance of. Spartina Alterniflora 1983, 49, 77-83.

17. Gao, B.C. NDWI-A normalized difference water index for remote sensing of vegetation liquid water from space. Remote Sens. Environ. 1996, 58, 257-266. [CrossRef]

18. Rodríguez-Pérez, J.R.; Riaño, D.; Carlisle, E.; Ustin, S.; Smart, D.R. Evaluation of hyperspectral reflectance indexes to detect grapevine water status in vineyards. Am. J. Enol. Vitic. 2007, 58, 302-317.

19. Fensholt, R.; Sandholt, I. Derivation of a shortwave infrared water stress index from MODIS near-and shortwave infrared data in a semiarid environment. Remote Sens. Environ. 2003, 87, 111-121. [CrossRef]

20. Zarco-Tejada, P.J.; Ustin, S. Modeling canopy water content for carbon estimates from MODIS data at land EOS validation sites. In Proceedings of the IGARSS 2001 Scanning the Present and Resolving the Future, IEEE 2001 International Geoscience and Remote Sensing Symposium (Cat. No. 01CH37217), Sydney, Australia, 9-13 July 2001; Volume 1, pp. 342-344.

21. Elvidge, C.D.; Lyon, R.J. Estimation of the vegetation contribution to the $1 \cdot 65 / 2 \cdot 22 \mu \mathrm{m}$ ratio in airborne thematic-mapper imagery of the Virginia Range, Nevada. Int. J. Remote Sens. 1985, 6, 75-88. [CrossRef]

22. Gitelson, A.; Kaufman, Y.; Stark, R.; Rundquist, D. Novel algorithms for remote estimation of vegetation fraction. Remote Sens. Environ. 2002, 80, 76-87. [CrossRef]

23. Peñuelas, J.; Filella, I.; Biel, C.; Serrano, L.; Save, R. The reflectance at the $950-970 \mathrm{~nm}$ region as an indicator of plant water status. Int. J. Remote Sens. 1993, 14, 1887-1905. [CrossRef]

24. Peñuelas, J.; Pinol, J.; Ogaya, R.; Filella, I. Estimation of plant water concentration by the reflectance water index WI (R900/R970). Int. J. Remote Sens. 1997, 18, 2869-2875. [CrossRef]

25. Dube, A.C.O.M.T. Remote sensing leaf water stress in coffee (Coffea arabica) using secondary effects of water absorption and random forests. Phys. Chem. Earth Parts A/B/C 2017, 317-324. [CrossRef]

26. Huang, S.; Tang, L.; Hupy, J.P.; Wang, Y.; Shao, G. A commentary review on the use of normalized difference vegetation index (NDVI) in the era of popular remote sensing. J. For. Res. 2021, 32, 1-6. [CrossRef]

27. Aparicio, N.; Villegas, D.; Casadesus, J.; Araus, J.; Royo, C. Spectral vegetation indices as nondestructive tools for determining durum wheat yield. Agron. J. 2000, 92, 83-91. [CrossRef]

28. Gitelson, A.; Merzlyak, M.; Chivkunova, O. Optical properties and nondestructive estimation of anthocyanin content in plant leaves. Photochem. Photobiol. 2001, 74, 38-45. [CrossRef] 
29. Zarco-Tejada, P.; González-Dugo, V.; Berni, J. Fluorescence, temperature and narrow-band indices acquired from a UAV platform for water stress detection using a micro-hyperspectral imager and a thermal camera. Remote Sens. Environ. 2012, 117, 322-337. [CrossRef]

30. Tucker, C. Red and photographic infrared linear combinations for monitoring vegetation. Remote Sens. Environ. 1979, 8, 127-150. [CrossRef]

31. Stimson, H.; Breshears, D.; Ustin, S.; Kefauver, S. Spectral sensing of foliar water conditions in two co-occurring conifer species: Pinus edulis and Juniperus monosperma. Remote Sens. Environ. 2005, 96, 108-118. [CrossRef]

32. Meo, M. Physiological responses of eucalyptus nitens $\times$ nitens under experimentally imposed water stress. South. For. 2010, 72, 63-68. [CrossRef] 